Western University

Scholarship@Western

Family Medicine Publications

Family Medicine Department

$5-2015$

\title{
The Impact of Childhood Symptoms of Conduct Disorder on Driver Aggression in Adulthood
}

Christine Wickens

Centrefor Addiction and Mental Health, christine.wickens@camh.ca

Evelyn R. Vingilis

Western University, evingili@uwo.ca

Robert Mann

Centre for Addiction and Mental Health, Robert.Mann@camh.ca

Patricia Erickson

University of Toronto, pat.erickson@utoronto.ca

Maggie Toplak

York University

See next page for additional authors

Follow this and additional works at: https://ir.lib.uwo.ca/fammedpub

Part of the Medicine and Health Sciences Commons

Citation of this paper:

Wickens, Christine; Vingilis, Evelyn R.; Mann, Robert; Erickson, Patricia; Toplak, Maggie; Kolla, Natan; Seeley, Jane; Ialomiteanu, Anca; Stoduto, Gina; and Ilie, Gabriela, "The Impact of Childhood Symptoms of Conduct Disorder on Driver Aggression in Adulthood" (2015). Family Medicine Publications. 17.

https://ir.lib.uwo.ca/fammedpub/17 


\section{Authors}

Christine Wickens, Evelyn R. Vingilis, Robert Mann, Patricia Erickson, Maggie Toplak, Natan Kolla, Jane Seeley, Anca Ialomiteanu, Gina Stoduto, and Gabriela Ilie 


\title{
Running head: IMPACT OF CONDUCT DISORDER ON DRIVER AGGRESSION
}

The Impact of Childhood Symptoms of Conduct Disorder on Driver Aggression in Adulthood

Christine M. Wickens ${ }^{1,2}$, Evelyn Vingilis ${ }^{3}$, Robert E. Mann ${ }^{1,2}$, Patricia Erickson ${ }^{4,5}$, Maggie E. Toplak ${ }^{6}$, Nathan J. Kolla ${ }^{1,7}$, Jane Seeley ${ }^{3}$, Anca Ialomiteanu ${ }^{1}$, Gina Stoduto ${ }^{1}$, and Gabriela Ilie ${ }^{1,8}$

1 -Centre for Addiction and Mental Health, Toronto, Ontario, Canada

2 - Dalla Lana School of Public Health, University of Toronto, Toronto, Ontario, Canada

3 -Schulich School of Medicine and Dentistry, the University of Western Ontario, London, Ontario, Canada

4 - Centre for Criminology and Sociolegal Studies, University of Toronto, Toronto, Ontario, Canada

5 - Department of Sociology, University of Toronto, Toronto, Ontario, Canada

6 -York University, Toronto, Ontario, Canada

7 - University of Toronto, Toronto, Ontario, Canada

8 - St. Michael's Hospital, Toronto, Ontario, Canada

\author{
AUTHORS' NOTE: \\ Correspondence concerning this article should be addressed to: \\ Dr. Christine M. Wickens \\ Centre for Addiction and Mental Health \\ Social and Epidemiological Research Department \\ 33 Russell Street, T417 \\ Toronto, Ontario M5S 2S1 \\ Canada \\ Email: Christine.Wickens@camh.nca \\ Telephone: (416) 535-8501 ext. 34711 \\ Fax: (416) 595-6899
}




\begin{abstract}
Background: Despite limited empirical investigation, existing scientific literature suggests that individuals with a history or current diagnosis of conduct disorder (CD) may be more likely to demonstrate reckless and aggressive driving. Much of the limited research in this field examines the impact of childhood CD on driver behaviour and collision risk in young adults. Few, if any, studies assess the impact of this disorder on driver behaviour beyond age 21 years. The current research is a population-based study of the impact of CD symptoms during childhood on the risk of engaging in driver aggression during adulthood.
\end{abstract}

Methods: Data are based on telephone interviews with 5,230 respondents who reported having driven in the past year. Data are derived from the 2011-2013 cycles of the CAMH Monitor, an ongoing cross-sectional survey of adults in Ontario, Canada aged 18 years and older. A binary logistic regression analysis of self-reported driver aggression in the previous 12 months was conducted, consisting of measures of demographic characteristics, driving exposure, problem substance use, alcohol- and drug-impaired driving, symptoms of attention deficit hyperactivity disorder, and childhood (before age 15) symptoms of CD.

Results: When entered with demographic characteristics, driving exposure, and other potential confounders, childhood symptoms of CD increased the odds of reporting driver aggression more than two-fold (adjusted OR=2.12). Exploratory analyses of the interaction between childhood symptoms of CD and age was not a significant predictor of driver aggression.

Conclusions: Results suggest that symptoms of CD during childhood are associated with significantly increased odds of self-reported driver aggression during adulthood. Limitations and future directions of the research are discussed.

Keywords: Driver aggression; aggressive driving; conduct disorder; conduct problems; attention deficit hyperactivity disorder; population survey 


\section{Introduction}

Driver aggression, including more serious forms such as road rage, has been identified as a significant traffic safety concern internationally (Hemenway et al., 2006; Mann et al., 2007; Sagar et al., 2013; Smart and Mann, 2002a; Wells-Parker et al., 2002; Wickens et al., 2013b). Nearly half of drivers in Ontario, Canada, report being victims of driver aggression in the past year, and about 1 in 10 report being victims of driver aggression serious enough to warrant a criminal charge (Smart et al., 200b). In addition to creating a stressful environment for road users, driver aggression increases collision risk and can result in injury and death (Mann et al., 2007; Smart and Mann, 2002b; Wells-Parker et al., 2002). Research has identified several individual and situational factors that increase the likelihood of driver aggression (Wickens et al., 2013a). Younger drivers, those with higher incomes, those who report more driving and driving high performance vehicles, those who live in denser urban environments, those who report more driving-related anger and negative cognitions, and those who themselves have been victims are more likely to report perpetrating driver aggression (Asbridge et al., 2003; Nesbitt and Conger, 2012; Nesbitt et al., 2007; Smart et al., 2003b; Smart et al., 2004; Wickens et al., 2011). Driver aggression is also associated with risky driving behaviour and experiencing negative or adverse driving events (Deffenbacher et al., 2001, 2003; Hennessy and Wiesenthal, 2002, 2004). Both males and females report similar levels of driver aggression after controlling for demographic factors (Hennessy and Wiesenthal, 2002; Hennessy et al., 2004; Wickens et al., 2012), while those who report more problematic use of alcohol and other drugs are more likely to report perpetration (Butters et al., 2005, 2006; Fierro et al., 2011; Mann et al., 2004; Yu et al., 2004).

Clinical and epidemiological studies have found that rates of psychiatric morbidity are higher in individuals who report involvement in driver aggression, including both the victims and 
perpetrators of these aggressive roadway events (Wickens et al., 2014a, in press). Attention deficit hyperactivity disorder (ADHD; Malta et al., 2005; Richards et al., 2006), alcohol and drug problems (Butters et al., 2005, 2006; Yu et al., 2004), and anxiety and mood disorders (Butters et al., 2006; Galovski et al., 2006; Smart et al., 2003a) have all been associated with increased risk of driver aggression. Individuals who report perpetration of driver aggression are more likely to report carrying weapons in their vehicles, suggesting a predisposition to violence (Hemenway et al., 2006). Disorders related to aggression and violence have also been assessed in aggressive drivers. Although few in number, these studies have identified an association between roadway aggression and disorders such as intermittent explosive disorder (Galovski et al., 2006), borderline personality disorder, and antisocial personality disorder ( Galovski et al., 2006; Malta et al., 2005; Sansone et al., 2010; Sansone and Sansone, 2010; Vaughn et al., 2011), which is unsurprising given that these conditions present high anger, interpersonal aggression, and impulsivity.

Conduct disorder $(\mathrm{CD})$ represents another form of psychiatric morbidity for which there is at least some evidence suggesting a link to driver aggression. CD is characterized by extreme externalizing behaviour and is diagnosed based on a prolonged pattern of antisocial behaviour that involves the violation of the basic rights of others or major age-appropriate societal norms or rules (American Psychiatric Association, 2013). CD typically emerges early in childhood/adolescence (Moffitt, 1993), and is associated with aggressive conduct toward others, property destruction, deceitfulness or theft, and serious violation of rules (American Psychiatric Association, 2013). The prevalence of CD ranges from $2 \%$ to more than $10 \%$, with a median estimate of 4\% (American Psychiatric Association, 2013; Costello et al., 2005). Longitudinal studies have found that CD is associated with earlier mortality (Laub and Vaillant, 2000); lower 
educational attainment (Fergusson and Horwood, 1998; Fergusson et al., 2005); greater unemployment or financial difficulty (Colman et al., 2009; Fergusson and Horwood, 1998; Fergusson et al., 2005); greater involvement with criminal activity (Fergusson et al., 2005); increased sexual risk-taking behaviour (Bardone et al., 1998; Fergusson et al., 2005); increased risk of separation/divorce (Colman et al., 2009; Olino et al., 2010); and lower levels of peer support, life satisfaction, coping skills, and global functioning (Colman et al., 2009; Olino et al., 2010).

In many cases, the relationship between $\mathrm{CD}$ in youth and negative outcome variables in adulthood is partially or fully mediated by adult antisocial behaviour (Olino et al., 2010), which highlights the importance of reducing the progression from conduct problems in adolescence to antisocial behaviour in adulthood as a means of improving psychosocial outcomes. The presence of callous-unemotional (CU) traits in conjunction with conduct problems is currently being studied as a possible explanation for the heterogeneity in progression from CD in childhood to adult antisocial behaviour. This research has produced mixed results, demonstrating both increases and decreases in deviant social cognition (e.g., prosocial thinking, empathy, hostile attributions) in children with both conduct problems and CU traits (Waschbusch et al., 2007). Nonetheless, impaired social cognition represents a potential mechanism by which CD may increase risk of driver aggression.

A series of cohort studies conducted in New Zealand provided evidence to suggest that those with a history or current diagnosis of CD are also more likely to demonstrate reckless and aggressive driving. Nada-Raja et al. (1997) examined the association between various psychiatric disorders and driver offences using data from the Dunedin Multidisciplinary Health and Development Study (DMHDS). This study followed the health, behaviour, and development of a 
cohort of children who were born between April 1, 1972 and March 31, 1975 at a hospital in Dunedin, New Zealand. Nada-Raja et al. (1997) divided the cohort based on responses to the Diagnostic Interview Schedule for Children (Costello et al., 1982) and a self-report delinquency scale (Moffitt and Silva, 1988), which was administered to cohort members at age 15 years. One group of cohort members consisted of those who met Diagnostic and Statistical Manual of Mental Disorders (DSM)-III criteria for conduct or oppositional disorder. Driver offences committed between ages 15 and 18 years were assessed through both self-report and examination of participants' official driving records. When examining official records, relative to nonconduct-disordered male drivers, males with $\mathrm{CD}$ at age 15 years reported more offences related to the graduated driver licensing system (GDLS), more licence offences unrelated to the GDLS (e.g., driving without a licence), and more alcohol-related driving offences. They were also more likely to report having been charged with one or more offences. Female drivers with $\mathrm{CD}$ at age 15 years were more likely than female drivers without $\mathrm{CD}$ to have committed more licence offences unrelated to the GDLS, but this result was based on a very small sample size, limiting the conclusions that could be drawn from the results. When examining self-reported driver offences, males with $\mathrm{CD}$ at age 15 years were more likely to drive without a licence, to not wear a seatbelt, and to break conditions of their learner's permit; however, they were no more likely to drive within $2 \mathrm{~h}$ of consuming alcohol and no more likely to be involved in a crash than other male drivers. Female drivers with $\mathrm{CD}$ at age 15 years were more likely to drive without a licence, but were otherwise similar to other female drivers. Among their conclusions, the authors suggested that adolescents with a history of conduct problems are significantly more likely than their peers to commit traffic offences. 
Also based on the DMHDS cohort, Begg et al. (1999) examined self-reported crash and injury data between ages 18 and 21 years. Results from this study were not as straightforward as those of Nada-Raja et al. (1997). Although both male and female drivers with CD at age 18 years were more likely to experience a serious injury unrelated to driving, they were no more likely to be involved in a motor vehicle collision. Female drivers with $\mathrm{CD}$ at age 15 years were more than twice as likely as other female drivers to be involved in a crash, whereas male drivers with CD at age 15 years were less likely to be involved in a crash. According to the authors, subsequent analyses suggested that collinearity between CD and attention deficit disorder in the male sample may have accounted for this inconsistency.

Woodward et al. (2000) analysed data from the Christchurch Health and Development Study (CHDS) which followed a sample of children born in Christchurch, New Zealand over a 4month period during 1977. This analysis focused on the impact that attentional difficulties measured at age 13 years had on driving-related outcomes at age 21 years; results indicated that conduct problems at age 13 years contributed to several negative driving-related outcomes. The presence of conduct problems was a significant covariate in the prediction of drink-driving arrests, number of police contacts for driving offences, and traffic violations. In another analysis of the CHDS data, Fergusson et al. (2003) found a linear trend between the presence of conduct problems at age 8 years and the number of risky driving behaviours reported between ages 18 and 21 years; however, the presence of conduct problems was not a significant predictor in the multivariate analysis.

In addition to cohort studies, other research paradigms have also shed light on the question of how CD impacts driving-related outcomes. Barkley et al. (1993) examined drivers with and without attention deficit hyperactivity disorder (ADHD) to identify driving-related 
implications of ADHD. However, their sample had a very high level of CD and oppositional defiant disorder (ODD) comorbidity. As part of their analysis, Barkley et al. (1993) assessed the relative contribution of all three disorders to negative driving-related outcomes and found that $\mathrm{CD}$ was a significant predictor of driving without a licence, crash-related injuries, and traffic citations. Similar results were found by Malta et al. (2005) in a study which compared the prevalence of psychiatric diagnoses among undergraduate students self-reporting as high versus low in driver aggression. The groups were matched according to age and gender. A number of lifetime and current psychiatric disorders were more prevalent among aggressive drivers, including a lifetime prevalence of CD. Lastly, Redelmeier et al. (2010) conducted a populationbased case-control study, examining male youth between ages 16 and 19 years hospitalized for road trauma (cases) or appendicitis (controls) in Ontario, Canada between April 1, 2002 and March 31, 2009. Using universal health care databases, the researchers found that a history of disruptive behaviour disorders (i.e. CD or ODD) was more frequent among cases than controls, and was associated with a one-third increase in the relative risk of serious road trauma.

The existing research suggests that there may be an impact of CD in childhood and adolescence on driving-related outcomes in adulthood; however, the available literature is limited in quantity, includes only one study of population-level data, and assesses outcomes only up to age 21 years. The purpose of the current study was to assess the relationship between CD symptoms during childhood and the risk of engaging in minor driver aggression during adulthood in a population-level dataset. The analysis included variables previously identified as risk factors for driver aggression including demographic variables (Wickens et al., 2013a), problem substance use (Butters et al., 2005, 2006; Yu et al., 2004), alcohol- and drug-impaired 
driving (Yu et al., 2004), and possible ADHD (Malta et al., 2005; Richards et al., 2006). As well, ADHD is commonly comorbid with CD (Jensen et al., 1997).

\section{Material and methods}

\subsection{Sample}

Data are based on telephone interviews with 5230 respondents who reported having driven a vehicle in the past year. Data are derived from the 2011-2013 cycles of the Centre for Addiction and Mental Health (CAMH) Monitor, an ongoing cross-sectional survey of adults in Ontario, Canada aged 18 years and older. The survey employs random-digit-dialling (RDD) methods via Computer Assisted Telephone Interviewing. Because the sampling frame used a listassisted RDD (instead of landline numbers only), cellular telephones, newly listed and unlisted numbers were also included. Each annual cycle consists of four independent quarterly samples with approximately 750 completions each. The annual response rate varied from 48 to $51 \%$. The data were weighted to adjust for varying selection probabilities, regional representation, and a final post-stratification adjustment to restore the age by sex distribution based on the most recently available census figures. The weighted sample is considered representative of the noninstitutionalized Ontario adult population (see Ialomiteanu and Adlaf (2012, 2013, 2014) for sampling design details). The institutional research ethics committee at CAMH has approved the survey annually.

\subsection{Variables}

Demographic variables included sex $(\operatorname{coded} 0=$ female, $1=$ male $)$, age (continuous variable), marital status (coded $1=$ married or common law, $2=$ previously married, $3=$ never married), income $($ coded $1=<\$ 30,000,2=\$ 30,000-49,999,3=\$ 50,000-79,999,4=\$ 80,000+$, $5=$ not stated), and region of residence (comprised of six regions in Ontario: $1=$ Toronto, $2=$ 
Central East, 3 = Central West, $4=$ West, $5=$ East, $6=$ North). Weekly driving distance, included as a control for differences in exposure, was treated as a continuous variable.

Problem alcohol use was measured using the Alcohol Use Disorders Indentification Test (AUDIT; Babor et al., 2001; Saunders et al., 1993), developed by the World Health Organization as a screening instrument. The AUDIT was designed to detect problem drinkers at the less severe end of the spectrum of alcohol problems, and has been demonstrated to be a highly valid measure with strong internal consistency and test-retest reliability (Babor et al., 2001). The AUDIT consists of ten items asking about the frequency, volume, and pattern of alcohol consumption, indicators of dependence, and adverse consequences associated with drinking. A score of 8 or more on the AUDIT is the validated threshold used to designate a hazardous or harmful level of drinking. For the current analysis, responses were dichotomized into those respondents reporting hazardous or harmful drinking levels versus those not reporting such risky behaviour (coded $0=$ no hazardous or harmful drinking, 1 = hazardous or harmful drinking).

Problem cannabis use was measured using the cannabis involvement sub-score of the Alcohol, Smoking and Substance Involvement Screening Test (ASSIST), also developed by the World Health Organization (WHO ASSIST Working Group, 2002). Asked of all respondents who self-identified as having used cannabis in the past three months, this 6-item subscale assesses the risk of experiencing health and other adverse consequences (e.g. social, financial, legal, relationship) from their current pattern of cannabis use. The ASSIST has strong demonstrated internal consistency and test-retest reliability (WHO ASSIST Working Group, 2002), as well as good concurrent, construct, discriminative and predictive validity (Humeniuk and Ali, 2006). For the current analysis, responses were dichotomized into those respondents 
with no risk or a low risk of developing health and other problems versus those respondents with a moderate or high risk (coded $0=$ no/low risk, $1=$ moderate/high risk).

Two measures of impaired driving were included. Past-year driving after drinking was measured by asking participants: 'during the past 12 months, have you driven a motor vehicle after having two or more drinks in the previous hour?' (coded $0=$ no, $1=$ yes). Driving after cannabis use in the past year was measured by asking participants: 'during the past 12 months, have you driven a motor vehicle within an hour of using cannabis, marijuana or hash?' (coded 0 $=$ no, $1=$ yes $)$.

Possible ADHD was assessed using the Adult ADHD Self-Report Scale-V1.1, developed by Kessler et al. (2005) in conjunction with a revision of the World Health Organization Composite Diagnostic Interview. This validated screener (Kessler et al., 2007) includes six of 18 items found to be most predictive of a diagnosis of ADHD as per the DSM-IV criteria. Items are rated on a 5-point Likert-type scale scored 0-4. Item scores were summed, and a cutoff score of greater than 13 was considered a positive indication of ADHD (coded $0=$ no, $1=$ yes).

Symptoms of CD were assessed with five items taken from the DSM-IV (American Psychiatric Association, 2000) assessment for antisocial personality disorder (APD); a diagnosis of APD requires evidence of CD with onset before age 15 years. Participants were asked: 'before you were 15 years old, did you: (1) repeatedly skip school or run away from home overnight? (2) Repeatedly lie, cheat, or steal? (3) Start fights or bully, threaten, or intimidate others? (4) Deliberately destroy things or start fires? (5) Deliberately hurt animals or people?' Participants who responded 'yes' to at least two of the questions were classified as likely having had CD (i.e. probable $\mathrm{CD})$ as a child (coded no $=1$, yes $=2)$. 
The key outcome variable was engaging in minor driver aggression. Participants were asked: 'during the past 12 months, either as a driver or a passenger, how many times have you shouted, cursed, or made rude gestures at a driver or passenger in another vehicle?' (coded no = 0 , yes $=1$ ). Conversion of continuous data to a binary format, including conversion of responses to the minor driver aggression question, was done in response to non-normality in the distribution of data that would have resulted in the violation of statistical assumptions.

\subsection{Analyses}

Design-based analyses were conducted using Taylor Series Linearization found in STATA11 software. Thus, all estimates and statistical tests were corrected for the sampling design. The data were screened such that 'do not know' responses and refusals were excluded from analyses. The weighted sample size was used when reporting percentages, and these are considered representative of the population surveyed. Data on prevalence of driver aggression by demographic factors and risk factors were examined through design-based $F$-test analyses. Logistic regression analysis was used to assess the impact of probable CD before age 15 years on driver aggression in adulthood when entered with demographic factors, driving exposure, problem substance use, alcohol- and drug-impaired driving, and possible ADHD.

\section{Results}

In the current sample, the prevalence of probable CD before age 15 years was 7.4 percent. Table 1 presents self-reported driver aggression by demographic characteristics, driving exposure, problem substance use, alcohol- and drug-impaired driving, possible ADHD, and probable CD before age 15 years. The overall prevalence of driver aggression was 43.7 percent. Based on the univariate analyses, self-reported driver aggression was more prevalent among males, those who had never been married, and those with higher incomes. Motorists who 
reported engaging in driver aggression were younger and reported a greater number of kilometres driven weekly. Driver aggression was also more prevalent among those reporting harmful or hazardous levels of alcohol consumption, problem cannabis use, driving after drinking, and driving after cannabis use. As well, driver aggression was more prevalent among those reporting symptoms of ADHD and childhood symptoms of CD.

A binary logistic regression analysis (svy: logit) (Lee and Forthofer, 2006) of the relationship between probable $\mathrm{CD}$ before age 15 years and driver aggression in adulthood was conducted, while simultaneously entering the influences of sex, age, marital status, income, region of residence, driving exposure, problem substance use, driving after drinking, driving after cannabis use, and possible ADHD (Table 2). Before the logistic regression model was conducted, markers for multicollinearity were assessed (Field, 2005) and were indicative of an absence of multicollinearity. The $F$-adjusted mean residual goodness-of-fit test for the final model was not significant, indicating good fit. The odds of self-reported driver aggression for those reporting childhood symptoms of $\mathrm{CD}$ were more than doubled (adjusted OR $=2.12,95 \%$ $\mathrm{CI}=1.55,2.90, p<.001)$ after controlling for potential confounders.

Preliminary analyses of the CAMH Monitor data from 2011 to 2012 had identified a significant interaction between probable $\mathrm{CD}$ and age, suggesting that the association between childhood symptoms of CD and self-reported driver aggression declined over the lifespan (Wickens et al., 2014b). Given that the current results from the binary logistic regression analysis using the larger 2011-2013 dataset had indicated increased odds of driver aggression associated with probable $\mathrm{CD}$ before age 15 years and decreased odds of driver aggression associated with age, the possible interaction between these variables was assessed using the larger 2011-2013 
dataset. Contrary to the results of the preliminary analyses using the 2011-2012 dataset, the interaction was not significant in the larger sample.

\section{Discussion}

Both univariate and multivariate analyses showed that, in a representative adult population sample, probable CD before age 15 years was associated with significantly higher odds of engaging in driver aggression. Specifically, after controlling for a number of potential confounders, the odds of self-reported driver aggression more than doubled among respondents reporting childhood symptoms of $\mathrm{CD}$. These results clearly identify a potentially important relationship between conduct problems in early adolescence and roadway aggression in adulthood. Exploratory analyses investigating possible changes in this relationship across different stages of the lifespan failed to find a statistically significant interactive effect. Despite what appeared to be a declining association between childhood CD symptoms and driver aggression across the lifespan, this interactive effect was not statistically significant in the current sample. Further research is needed to address the question of whether the association of childhood CD symptoms with driver aggression declines with age.

The results of the multivariate analyses also provide confirmation that driver aggression is influenced by other factors as well. Older age, lower income, and lower rates of driving exposure were associated with reduced rates of driving aggression, as has been reported by previous studies (Smart et al., 2003b,, 2004; Wickens et al., 2011). Consistent with previous findings (Butters et al., 2005, 2006; Fierro et al., 2011; Mann et al., 2004), drivers who were experiencing alcohol and cannabis problems were more likely to report driver aggresion. However, while some studies have reported a link between ADHD and driving problems such as collisions (Barkley et al., 1993), the current finding of no significant relationship between 
ADHD and driver aggression is consistent with recent findings of no strong impact of ADHD on driving problems and collision risk (Vingilis et al., 2014). The current study is also consistent with a recent meta-analysis that found that $\mathrm{CD}$ and other externalizing behaviours substantially mediated the relationship between ADHD and driving problems and collision risk (Vaa, 2014). Therefore, it is possible that in the current study, symptoms of ADHD and CD accounted for common variance in driver aggression, and that the effects of ADHD symptoms on driver aggression seen in univariate analyses may have resulted from the comorbidity of CD with ADHD. Nevertheless, this study provides additional support for the suggestion that neuropsychiatric issues are important factors in road safety (e.g. Ilie et al., submitted; Wickens et al., 2014a).

Several limitations of the current research must be noted. First, it is important to reiterate that the data are derived from a cross-sectional population survey, are correlational in nature, and therefore, cause-and-effect conclusions cannot be drawn. Second, the driver aggression question on which these analyses are based refers to aggression expressed while being a driver or a passenger. Nonetheless, aggression by passengers still represents a threat to roadway safety, and passenger aggression can elicit retaliatory aggression by the offended driver. Third, these data were collected through self-report telephone interviews, which may have introduced bias such as underreporting of driver aggression due to socially desirable responding. Participants may also have had difficulty recalling incidents of conduct problems prior to age 15 years, particularly for older respondents. Fourth, the measure of CD symptoms is a screening tool that is not designed as a diagnostic measure. It also cannot distinguish between types of CD (i.e. childhood-onset, adolescent-onset, unspecified-onset). Not all cases of CD persist into adulthood, but childhoodonset $\mathrm{CD}$ is considered by some to pose greater risk of lifecourse persistence (Goldstein et al., 
2006; Moffitt, 1993; Moffitt et al., 2002) and may, therefore, have a significantly greater impact on driver aggression than is reflected by the odds ratio presented here. Fifth, it cannot be determined whether eligible respondents who declined to participate would have responded in a similar fashion to those respondents included in the final sample. Finally, telephone surveys are limited by the unavoidable exclusion of certain groups within the population including the homeless and those who reside in prisons, hospitals, and military establishments.

Although an association between symptoms of CD before age 15 years and driver aggression in adulthood has been identified, further research will be needed to understand the nature of this relationship. Other variables may mediate the relationship between symptoms of $\mathrm{CD}$ and driver aggression, including perhaps personality, adult antisocial behaviour and other symptoms of psychopathology (Olino et al., 2010; Waschbusch et al., 2007). It would also be informative to determine if there is a relationship between childhood symptoms of CD and the frequency or severity of perpetrated driver aggression. Nonetheless, there are practical implications of the identified association between symptoms of CD and driver aggression.

Interventions for CD can take many forms including various types of therapy, home, school, and community-based programs, residential and hospital treatment, and social services (Kazdin, 1993). Given the impact that probable CD can have on driver aggression, and the likely relationship between CD and collision risk (Begg et al., 1999; Redelmeier et al., 2010), it may be advisable to ensure that special attention within treatment be paid to aggression and outbursts behind the wheel of a vehicle. Likewise, while a discussion of roadway anger and aggression may be important for all parents to have with their children when they are in the process of obtaining a driver's licence, this may be particularly important for parents of adolescents exhibiting symptoms of CD. It may also be prudent for these parents to exercise more stringent 
supervision of their children's driving behaviour. This type of parental intervention early in a novice driver's training may help to reduce the impact of childhood symptoms of CD on driver aggression in both adolescence and adulthood. Finally, it may also be beneficial to screen for CD symptoms in any prevention or remedial program designed to reduce driver aggression. A more focused or specialized curriculum may prove more effective for program participants with a history of CD symptoms, who are at greater risk of engaging in driver aggression. Future research should consider each of these potential preventive approaches to addressing driver aggression among those exhibiting symptoms of CD. 


\section{Acknowledgments}

This research was supported by a Canadian Institutes for Health Research (CIHR) grant (MOP102537). This research was also partly supported by a grant from AUTO21, a member of the Networks of Centres of Excellence (NCE) program that is administered and funded by the CIHR, the Natural Sciences and Engineering Research Council (NSERC), and the Social Sciences and Humanities Research Council (SSHRC), in partnership with Industry Canada. 


\section{References}

American Psychiatric Association. (2000). Diagnostic and statistical manual of mental disorders (4th ed., text rev.). Washington, DC: American Psychiatric Association.

American Psychiatric Association. (2013). Diagnostic and statistical manual of mental disorders (5 $5^{\text {th }}$ ed.). Arlington, VA: American Psychiatric Association. Web access date: 1 June 2013. dsm.psychiatryonline.org

Asbridge, M., Smart, R. G., \& Mann, R. E. (2003). The 'homogamy’ of road rage: Understanding the relationship between victimization and offending among aggressive and violent motorists. Violence and Victims, 18, 517-531.

Babor, T. F., Higgins-Biddle, J. C., Saunders, J. B., \& Monteiro, M. G. (2001). AUDIT: The Alcohol Use Disorders Identification Test. Guidelines for use in primary care. Geneva: World Health Organization.

Bardone, A., Moffitt, T., Caspi, A., Dickson, N., Stanton, W., \& Silva, P. (1998). Adult physical health outcomes of adolescent girls with conduct disorder, depression, and anxiety. Journal of the American Academy of Child \& Adolescent Psychiatry, 37, 594-601.

Barkley, R. A., Guevremont, D. C., Anastopulos, A. D., DuPaul, G. J., \& Shelton, T. L. (1993). Driving-related risks and outcomes of attention deficit hyperactivity disorder in adolescents and young adults: A 3- to 5-year follow-up survey, Pediatrics, 92, 212-218.

Begg, D. J., Langley, J. D., \& Williams, S. M. (1999). A longitudinal study of lifestyle factors as predictors of injuries and crashes among young adults. Accident Analysis and Prevention, $31,1-11$.

Butters, J., Smart, R. G., \& Mann, R. E. (2006). Assessing road rage victimization and perpetration in the Ontario adult population: The impact of illicit drug use and psychiatric 
distress. Canadian Journal of Public Health, 97, 96-99.

Butters, J., Smart, R. G., Mann, R. E., \& Asbridge, M. (2005). Illicit drug use, alcohol use and problem drinking among frequent and infrequent road ragers. Drug and Alcohol Dependence, 80, 169-175.

Colman, I., Murray, J., Abbott, R. A., Maughan, B., Kuh, D., Croudace, T. J., \& Jones, P. B. (2009). Outcomes of conduct problems in adolescence: 40 year follow-up of national cohort. BMJ, 338, a2981.

Costello, A., Edelbrock, C., Kalas, R., Kessler, M., \& Klaric, S. A. (1982). Diagnostic Interview Schedule for Children (DISC), Contract No. RFP-DB-81-0027. Bethesda, MD: National Institute of Mental Health.

Costello, E. J., Egger, H., \& Angold, A. (2005). 10-year research update review: the epidemiology of child and adolescent psychiatric disorders, I: methods and public health burden. Journal of the American Academy of Child \& Adolescent Psychiatry, 44, 972 986.

Deffenbacher, J. I., Deffenbacher, D. M., Lynch, R. S., \& Richards, T. L. (2003). Anger, aggression, and risky behavior: A comparison of high and low anger drivers. Behaviour Research and Therapy, 41, 701-718.

Deffenbacher, J. L., Lynch, R. S., Oetting, E. R., \& Yingling, D. A. (2001). Driving anger. Correlates and a test of state-trait theory. Personality and Individual Differences, 31, $1321-1331$.

Fergusson, D., \& Horwood, L. (1998). Early conduct problems and later life opportunities. Journal of Child Psychology and Psychiatry, 39, 1097-1108. 
Fergusson, D., Horwood, J., \& Ridder, E. (2005). Show me the child at seven: the consequences of conduct problems in childhood for psychosocial functioning in adulthood. Journal of Child Psychology and Psychiatry, 46, 837-849.

Fergusson, D., Swain-Campbell, N., \& Horwood, J. (2003). Risky driving behaviour in young people: prevalence, personal characteristics and traffic accidents. Australian and New Zealand Journal of Public Health, 27, 337-342.

Field, A. (2005). Discovering statistics using SPSS. Thousand Oaks, CA: SAGE Publications, Inc.

Fierro, I., Morales, C., \& Alvarez, F. J. (2011). Alcohol, illicit drug use, and road rage. Journal of Studies on Alcohol and Drugs, 72, 185-193.

Galovski, T. E., Malta, L. S., \& Blanchard, E. B. (2006). Road rage: Assessment and treatment of the angry, aggressive driver. Washington, DC: American Psychological Association.

Goldstein, R. B., Grant, B. F., Ruan, J., Smith, S. M., \& Saha, T. D. (2006). Antisocial personality disorder with childhood- vs adolescence-onset conduct disorder: Results from the National Epidemiologic Survey on Alcohol and Related Conditions. Journal of Nervous and Mental Disease, 194, 667-675.

Hemenway, D., Vriniotis, M., \& Miller, M. (2006). Is an armed society a polite society? Guns and road rage. Accident Analysis and Prevention, 38, 687-695.

Hennessy, D. A., \& Wiesenthal, D. L. (2002). Aggression, violence, and vengeance among male and female drivers. Transportation Quarterly, 56, 65-75.

Hennessy, D. A., \& Wiesenthal, D. L. (2004). Age and vengeance as predictors of mild driver aggression. Violence and Victims, 19, 469-477. 
Hennessy, D. A., Wiesenthal, D. L., Wickens, C. M., \& Lustman, M. (2004). The impact of gender and stress on traffic aggression: Are we really that different?. In J. P. Morgan (Ed.), Focus on aggression research (pp. 157-174). Hauppauge, NY: Nova Science Publishers.

Humeniuk, R., \& Ali, R. (2006). Validation of the Alcohol, Smoking and Substance Involvement Screening Test (ASSIST) and pilot brief intervention: a technical report of phase II findings of the WHO ASSIST Project. Web access date: 14 August 2014. http://www.who.int/substance_abuse/activities/assist_technicalreport_phase2_final.pdf

Ialomiteanu, A., \& Adlaf, E. M. (2012). CAMH Monitor 2011: Metadata User's Guide. Toronto, Canada: Centre for Addiction and Mental Health.

Ialomiteanu, A., \& Adlaf, E. M. (2013). CAMH Monitor 2012: Metadata User’s Guide. Toronto, Canada: Centre for Addiction and Mental Health.

Ialomiteanu, A., \& Adlaf, E. M. (2014). CAMH Monitor 2013: Metadata User's Guide. Toronto, Canada: Centre for Addiction and Mental Health.

Ilie, G., Mann, R. E., Ialomiteanu, A., Adlaf, E. M., Stoduto, G., Hamilton, H., Wickens, C. M., Rehm, J., \& Cusimano, M. (submitted). Traumatic brain injury, driver aggression and collisions in Canadian adults. Accident Analysis and Prevention.

Jensen, P. S., Martin, D., \& Cantwell, D. P. (1997). Comorbidity in ADHD: Implications for Research, Practice, and DSM-V. Journal of the American Academy of Child \& Adolescent Psychiatry, 36, 1065-1079.

Kazdin, A. E. (1993). Treatment of conduct disorder: Progress and directions in psychotherapy research. Development and Psychopathology, 5, 277-310. 
Kessler, R. C., Adler, L., Ames, M., Demler, O., Faraone, S., Hiripi, E., Howes, M. J., Jin, R., Secnbik, K., Spencer, T., Ustun, T. B., \& Walters, E. E. (2005). The World Health Organization Adult ADHD Self-Report Scale (ASRS): A short screening scale for use in the general population. Psychological Medicine, 35, 245-256.

Kessler, R. C., Adler, L. A., Gruber, M. J., Sarawate, C. A., Spencer, T., \& Van Brunt, D. L. (2007). Validity of the World Health Organization Adult ADHD Self-Report Scale (ASRS). Screener in a representative sample of health plan members. International Journal of Methods in Psychiatric Research, 16, 52-65.

Laub, J. H., \& Vaillant, G. E. (2000). Delinquency and mortality: a 50-year follow-up study of 1,000 delinquent and non-delinquent boys. American Journal of Psychiatry, 157, 96-102.

Lee, E. S., \& Forthofer, R. N. (2006). Analyzing complex survey data (2 ${ }^{\text {nd }}$ ed.). Sage Publications, Inc. Web access date: 23 August 2011. http://www.sagepub.com/upmdata/6428_Chapter_6_Lee_(Analyzing)_I_PDF_7.pdf

Malta, L. S., Blanchard, E. B., \& Freidenberg, B. M. (2005). Psychiatric and behavioral problems in aggressive drivers. Behaviour Research and Therapy, 43, 1467-1484.

Mann, R. E., Smart, R. G., Stoduto, G., Adlaf, E. M., \& Ialomiteanu, A. (2004). Alcohol factors in road rage victims and perpetrators. Journal of Studies on Alcohol, 65, 161-168.

Mann, R. E., Zhao, J., Stoduto, G., Adlaf, E., Smart, R. E., \& Donovan, J. E. (2007). Road rage and collision involvement. American Journal of Health Behavior, 31, 384-391.

Moffitt, T. E. (1993). Adolescence-limited and life-course-persistent antisocial behavior: a developmental taxonomy. Psychological Review, 100, 674-701. 
Moffitt, T. E., Caspi, A., Harrington, H., \& Milne, B. J. (2002). Males on the life-coursepersistent and adolescence-limited antisocial pathways: Follow-up at age 26 years. Development and Psychopathology, 14, 179-207.

Moffitt, T. E., \& Silva, P. A. (1988). Self-reported delinquency: results from an instrument for New Zealand. Australia and New Zealand Journal of Criminology, 21, 227-240.

Nada-Raja, S., Langley, J. D., McGee, R., Williams, S. M., Begg, D. J., \& Reeder, A. I. (1997). Inattentive and hyperactive behaviors and driving offenses in adolescence. Journal of the American Academy of Child \& Adolescent Psychiatry, 36, 515-522.

Nesbit, S. M., \& Conger, J. C. (2012). Predicting aggressive driving behavior from anger and negative cognitions. Transportation Research Part F, 15, 710-718.

Nesbit, S. M., Conger, J. C., \& Conger, A. J. (2007). A quantitative review of the relationship between anger and aggressive driving. Aggression and Violent Behavior, 12, 156-176.

Olino, T. M., Seeley, J. R., \& Lewinsohn, P. M. (2010). Conduct disorder and psychosocial outcomes at age 30: Early adult psychopathology as a potential mediator. Journal of Abnormal Child Psychology, 38, 1139-1149.

Redelmeier, D. A., Chan, W. K., \& Lu, H. (2010). Road trauma in teenage male youth with childhood disruptive behavior disorders: A population based analysis. PLoS Medicine, 7, e1000369.

Richards, T. L., Deffenbacher, J. L., Rosén, L. A., Barkley, R. A., \& Rodricks, T. (2006). Driving anger and driving behavior in adults with ADHD. Journal of Attention Disorders, 10, 54-64. 
Sagar, R., Mehta, M., \& Ghugh, G. (2013). Road rage: An exploratory study on aggressive driving experience on Indian roads. International Journal of Social Psychiatry, 59, 407412.

Sansone, R. A., Lam, C., \& Wiederman, M. S. (2010). Road rage: Relationships with borderline personality and driving citations. International Journal of Psychiatry in Medicine, 40, 21 29.

Sansone, R. A., \& Sansone, L. A. (2010). Road rage: What's driving it? Psychiatry (Edgemont), 7, 14-18.

Saunders, J. B., Aasland, O. G., Babor, T. F., De la Fuente, J. R., \& Grant, M. (1993). Development of the Alcohol Use Disorders Identification Test (AUDIT): WHO collaborative project on early detection of persons with harmful alcohol consumption BII. Addiction, 88, 791-804.

Smart, R. G., Asbridge, M., Mann, R. E., \& Adlaf, E. M. (2003). Psychiatric distress among road rage victims and perpetrators. Canadian Journal of Psychiatry, 48, 681-688.

Smart, R. G., \& Mann, R. E. (2002a). Deaths and injuries from road rage: Cases in Canadian newspapers. Canadian Medical Association Journal, 167, 761-762.

Smart, R. G., \& Mann, R. E. (2002b). Is road rage a traffic safety problem? A review and research perspective. Traffic Injury Prevention, 3, 183-189.

Smart, R. G., Mann, R. E., \& Stoduto, G. (2003). The prevalence of road rage: Estimates from Ontario. Canadian Journal of Public Health, 94, 247-250.

Smart, R. G., Stoduto, G., Mann, R. E., \& Adlaf, E. M. (2004). Road rage experience and behaviour: Vehicle, exposure and driver factors. Traffic Injury Prevention, 5, 343-348. 
Vaa, T. (2014). ADHD and relative risk of accidents in road traffic: A meta-analysis. Accident Analysis and Prevention, 62, 415-425.

Vaughn, M. G., Define, R. S., DeLisi, M., Perron, B. E., Beaver, K. M., Fu, Q., \& Howard, M. O. (2011). Sociodemographic, behavioral, and substance use correlates of reckless driving in the United States: Findings from a national sample. Journal of Psychiatric Research, 45, 347-353.

Vingilis, E., Mann, R. E., Erickson, P., Toplak, M., Kolla, N., Seeley, J., \& Jain, U. (2014). Attention Deficit Hyperactivity Disorder, other mental health problems, substance use and driving: Examination of a population-based, representative Canadian sample. Traffic Injury Prevention, 15 (Supp.1), S1-S9.

Waschbusch, D. A., Walsh, T. M., Andrade, B. F., King, S., Carrey, N. J. (2007). Social problem solving, conduct problems, and callous-unemotional traits in children. Child Psychiatry and Human Development, 37, 293-305.

Wells-Parker, E., Ceminsky, J., Hallberg, V., Snow, R. W., Dunaway, G., Guiling, S., Williams, M., \& Anderson, B. (2002). An exploratory study of the relationship between road rage and crash experience in a representative sample of US drivers. Accident Analysis and Prevention, 34, 271-278.

WHO ASSIST Working Group. (2002). Alcohol, smoking and substance involvement screening test (ASSIST): Development, reliabiity and feasiblity. Addiction, 97, 1183-1194.

Wickens, C. M., Mann, R. E., Butters, J., Smart, R. G., \& Stoduto, G. (in press). Road Rage. In B. Puri \& I. Treasaden (Eds.), Forensic psychiatry. Hodder Arnold. 
Wickens, C. M., Mann, R. E., Stoduto, G., Ialomiteanu, A., Butters, J., \& Smart, R. G. (2012). Does gender moderate the relationship between driver aggression and risk factors? Accident Analysis and Prevention, 45, 10-18.

Wickens, C. M., Mann, R. E., Stoduto, G., Ialomiteanu, A., \& Smart, R. G. (2011). Age group differences in self-reported aggressive driving perpetration and victimization. Transportation Research Part F: Traffic Psychology and Behaviour, 14, 400-412.

Wickens, C. M., Mann, R. E., \& Wiesenthal, D. L. (2013). Addressing driver aggression: Contributions from psychological science. Current Directions in Psychological Science, 22, 386-391.

Wickens, C. M., Smart, R. G., \& Mann, R. E. (2014). The impact of depression on driver performance. International Journal of Mental Health and Addiction, 12, 524-537.

Wickens, C. M., Vingilis, E., Mann, R. E., Erickson, P., Toplak, M. E., Jain, U. R., Kolla, N., Seeley, J., Ialomiteanu, A., Stoduto, G., \& Ilie, G. (2014). The impact of childhood symptoms of conduct disorder on driver aggression across the lifespan. Proceedings of the $24^{\text {th }}$ Canadian Multidisciplinary Road Safety Conference, Vancouver, British Columbia, Canada.

Wickens, C. M., Wiesenthal, D. L., Hall, A., \& Roseborough, J. (2013). Driver anger on the information superhighway: A content analysis of online complaints of offensive driver behaviour. Accident Analysis and Prevention, 51, 84-92.

Woodward, L. J., Fergusson, D. M., \& Horwood, L. J. (2000). Driving outcomes of young people with attentional difficulties in adolescence. Journal of the American Academy of Child \& Adolescent Psychiatry, 39, 627-634. 
Yu, J., Evans, P. C., \& Perfetti, L. (2004). Road aggression among drinking drivers: Alcohol and non-alcohol effects on aggressive driving and road rage. Journal of Criminal Justice, 32, $421-430$. 
Table 1. Self-reported driver aggression by demographic variables, driving exposure, problem substance use, impaired driving, and probable $C D$ before age 15 years: Ontario CAMH Monitor, January 2011 - December 2013.

$\frac{\text { Driver Aggression }}{\text { a }^{\mathrm{a}}}$

TOTAL $^{\mathrm{d}}$

5230

43.7

$42.0,45.4$

DEMOGRAPHIC VARIABLES:

Sex

Female

2998

2232

Male

Age

mean (SD) Driver Aggression ${ }^{\mathrm{a}}$ No

3100

Driver Aggression ${ }^{\mathrm{a}}$ Yes

2037

Marital Status

Married/partner

Previously married

Never married

Income $^{\mathrm{e}}$

$<\$ 30,000$

$\$ 30,000$ - \$49,999

$\$ 50,000$ - $\$ 79,999$

$\$ 80,000+$

Not stated

Region of Residence

Toronto

Central East

Central West

West

East

North

\section{DRIVING EXPOSURE:}

Km driven-typical week (100s) ${ }^{\mathrm{f}}$

mean (SD) Driver Aggression ${ }^{a}$ No

Driver Aggression ${ }^{\mathrm{a}}$ Yes

3471

1043

665

458

641

1013

1961

1157

*

41.7

$39.5,43.9$

45.7

$43.1,48.2$

***

$49.4,51.1$

50.3

(18.0)

43.6

$42.9,44.4$

(13.7)

**

43.8

$41.9,45.8$

36.0

$32.2,40.1$

47.1

$42.1,52.1$

***

30.9

25.4, 37.1

34.8

$30.3,39.6$

43.1

$39.4,47.0$

51.5

$48.9,54.1$

35.8

$32.2,39.5$

741

870

922

892

912

893

42.4

$38.2,46.7$

43.6

$39.8,47.5$

47.2

$43.4,51.0$

42.3

$38.6,46.1$

43.4

$39.6,47.2$

39.5

$35.7,43.4$

2746

***

2.55

$2.39,2.72$

(4.02)

1899

3.41

(4.72)

$3.15,3.67$

PROBLEM SUBSTANCE USE:

Alcohol (AUDIT)

Not hazardous or harmful

4553

$* * *$

41.7

$39.9,43.5$ 
Hazardous or harmful

Cannabis (ASSIST)

No/low risk

Moderate/high risk

IMPAIRED DRIVING:

Driving After Drinking

No

Yes

Driving After Cannabis Use

No

Yes

MENTAL HEALTH:

Probable ADHD

No $($ score $\leq 13)$

Yes (score $>13$ )

Probable CD before age 15 years

No ( $<2$ symptoms)

Yes (2+ symptoms)
540

5023

198

4951

262

5141

74
59.1

$* * *$

42.4

65.9

$* * *$

42.7

57.1

**

43.1

63.5

$* * *$

4882

148

43.5

61.5

$* * *$

$41.0,44.5$

$49.7,64.2$

$41.4,44.8$

$50.0,75.2$

${ }^{\mathrm{a}}$ In the last 12 months.

${ }^{\mathrm{b}}$ Percentages reported are based on weighted sample size.

c $95 \%$ confidence intervals.

${ }^{\mathrm{d}}$ Respondents who report having driven a motor vehicle in the last 12 months.

${ }^{\mathrm{e}}$ Canadian dollars.

${ }^{\mathrm{f}}$ Driving distance was divided by 100 so that the adjusted odds ratio presented in Table 2 reflected the change in risk for each additional 100 kilometres of weekly driving.

Design-based $F$ statistical significance $* p<.05$; ** $p<.01 ; * * * p<.001$ 
Table 2. Logistic regression model of Driver Aggression: Ontario CAMH Monitor, January 2011 - December 2013.

Driver Aggression ${ }^{\text {a }}$ $(n=4275)$

\section{DEMOGRAPHIC VARIABLES:}

Sex $($ ref. $=$ female $)$

Age

Marital Status (ref. = married)

Previously married

Never married

Income ${ }^{\mathrm{e}}$ (ref. $\left.=<\$ 30,000\right)$

$\$ 30,000-49,999$

$\$ 50,000-79,999$

$\$ 80,000+$

Not stated

Region of Residence (ref. $=$ Toronto)

Central East

Central West

West

East

North

\section{DRIVING EXPOSURE:}

Km driven-typical week (100s) ${ }^{\mathrm{e}}$

$\underline{\mathrm{OR}^{\mathrm{b}, \mathrm{c}}}$

1.01

$.97 * * *$

$* *$

1.08

$.62 * *$

$* * *$

1.39

$1.55^{*}$

$2.03 * * *$

$1.52 *$

.97

1.08

.92

.95

.84

$1.42 *$

$1.69 *$

$1.09,1.84$

Alcohol (AUDIT) (ref = not hazardous or harmful)

Cannabis (ASSIST) $(\mathrm{ref}=$ no/low risk)
$.85,1.20$

$.97, .98$

$.85,1.38$

$.47, .81$

$.90,2.16$

$1.03,2.33$

$1.37,3.02$

$1.00,2.32$

$.74,1.28$

$.82,1.41$

$.70,1.21$

$.72,1.25$

$.63,1.11$
$1.02,1.06$

\section{IMPAIRED DRIVING:}

Driving After Drinking (ref $=$ no)

Driving After Cannabis Use ( $\mathrm{ref}=\mathrm{no})$

1.16

.86

MENTAL HEALTH:

Probable ADHD $(\mathrm{ref}=\mathrm{no})$

Probable CD before age 15 years ( $($ ef. $=$ no)

1.53

$2.12 * * *$

$.91,2.57$

$1.56,2.90$

1.45

$.83,2.52$

Constant $F(9,4249)=0.62, p=.78$

$F$-adjusted mean residual goodness-of-fit test

\footnotetext{
${ }^{\mathrm{a}}$ In the last 12 months.

${ }^{\mathrm{b}}$ Adjusted odds ratio.

${ }^{\mathrm{c}}$ Based on weighted sample size.
} 
d $95 \%$ confidence intervals.

${ }^{\mathrm{e}}$ Canadian dollars.

Ref. $=$ reference category.

Design-based $F$ statistical significance $* p<.05 ; * * p<.01 ; * * * p<.001$ 